\title{
Decoction of Chinese Herbal Medicine Fuzheng Kang-Ai Induces Lung Cancer Cell Apoptosis via STAT3/Bcl-2/Caspase-3 Pathway
}

\author{
Sumei Wang, ${ }^{1,2,3}$ Shunqin Long, ${ }^{1,3}$ Shujing Xiao, \\ Wanyin $W u(\mathbb{D}),{ }^{1,3}$ and Swei Sunny Hann $\mathbb{D}^{1,4}$ \\ ${ }^{1}$ Department of Oncology, Guangdong Provincial Hospital of Chinese Medicine, The Second Clinical Medical College, \\ Guangzhou University of Chinese Medicine, Guangzhou, Guangdong 510120, China \\ ${ }^{2}$ The Postdoctoral Research Station, Guangzhou University of Chinese Medicine, Guangzhou, Guangdong 510120, China \\ ${ }^{3}$ Guangdong Provincial Key Laboratory of Clinical Research on Traditional Chinese Medicine Syndrome, Guangzhou, \\ Guangdong, China \\ ${ }^{4}$ Laboratory of Tumor Biology, Guangdong Provincial Hospital of Chinese Medicine, The Second Clinical Medical Collage, \\ Guangzhou University of Chinese Medicine, Guangzhou, Guangdong 510120, China
}

Correspondence should be addressed to Wanyin Wu; wwanyin@126.com and Swei Sunny Hann; hann2012@outlook.com

Received 21 December 2017; Revised 11 March 2018; Accepted 27 March 2018; Published 25 June 2018

Academic Editor: Min Li

Copyright (C) 2018 Sumei Wang et al. This is an open access article distributed under the Creative Commons Attribution License, which permits unrestricted use, distribution, and reproduction in any medium, provided the original work is properly cited.

\begin{abstract}
Decoction of Chinese herbal medicine (CHM) Fuzheng Kang-Ai (FZKA for short) has been applied as adjuvant treatment strategy in advanced lung cancer patients for decades. We previously showed that FZKA decoction inhibited proliferation of non-small cell lung cancer (NSCLC) cells through activation of AMP-activated protein kinase alpha (AMPK $\alpha$ ) signaling pathway, followed by inducing insulin-like growth factor (IGF) binding protein 1 (IGFBP1) and forkhead homeobox type O3a (FOXO3a) proteins, and enhanced the inhibition effect of gefitinib in lung cancer cell growth via inactivating PI3-K/Akt-mediated suppressing of cell surface-associated mucin-1 (MUC1) expression. In this study, we investigated the molecular mechanism by which FZKA decoction affected cell apoptosis in lung cancer cells. Our results show that FZKA induced apoptosis in lung cancer cells. Mechanistically, FZKA activated the caspase-3, PARP, and caspase- 9 activities. Both antiapoptotic and proapoptotic proteins from Bcl-2 family were deregulated by FZKA exposure in lung cancer cells. In addition, FZKA reduced protein expressions of signal transducer and activator of transcription 3 (STAT3) and Jun activation domain-binding protein 1 (Jab1), while it concomitantly increased p21 protein. Moreover, the inhibitor of caspase-3 resisted the effect of FZKA on induction of apoptosis. Finally, exogenous overexpression of STAT3 overcame FZKA-inhibited protein expressions of Bcl-2 and myeloid cell leukemia-1 (Mcl-1) as well as Bax and blocked FZKA-induced activities of caspase-3 and caspase-9. Our results show that FZKA decoction promotes lung cancer cell apoptosis through STAT3/Bcl-2/caspase-3 signaling pathways. This study unveils potential novel molecular mechanism by which FZKA controls growth of human lung cancer cells.
\end{abstract}

\section{Introduction}

Lung cancer is a leading cause of cancer-related death in the world [1]. In China, lung cancer is the most frequently diagnosed cancer in males $(22.14 \%)$ and is the leading cause of cancer death in both males (27.21\%) and females (21.91\%) [2]. Despite major advances in combination treatments, the prognosis of non-small cell lung cancer (NSCLC) is still dismal and the 5-year survival rate with all stages and subtypes combined remains as low as $11 \%$ [3]. The Chinese herbal medicine (CHM) provides promising strategy for patients with late stage of lung cancer. In the last decades, many traditional Chinese herbs (TCH) with antitumor properties have drawn more attention due to their substantial efficacy, less drug resistance, and minimal toxicities, resulting in increase in quality of life and patient survival $[4,5]$. For example, Yangfei Kongliu Formula (YKF) combined with cisplatin significantly inhibited the growth and metastasis of lung cancer cells via TGF- $\beta 1$ pathway [6]. Homeopathic Psorinum-6x triggered apoptosis in lung cancer A549 cells 
thorough both upregulation and downregulation of relevant signal proteins, including $\mathrm{p} 53$, caspase-3, Bax, and $\mathrm{Bcl}-$ 2 [7]. However, the molecular mechanism underlying the therapeutic potential has not been well elucidated.

Fuzheng Kang-Ai (FZKA) decoction, a 12-herb traditional formula, was firstly prescribed by Dr. Wanyin $\mathrm{Wu}$ and has been used to treat NSCLC patients in Guangdong Provincial Hospital of Chinese Medicine for decades, which showed a positive impact on patients. Previous study showed that FZKA combined with gefitinib resulted in longer progression-free survival (PFS) with less toxicity than gefitinib alone [8]. Meanwhile, FZKA could enhance the disease control rate (DCR) as well as median survival time (MST) in NSCLC patients $[9,10]$. Mechanistically, we also found that FZKA inhibited growth of NSCLC cells through AMP-activated protein kinase alpha- (AMPK $\alpha-)$ mediated induction and interplay of insulin-like growth factor (IGF) binding protein 1 (IGFBP1) and forkhead homeobox type O3a (FOXO3a), demonstrating definite therapeutic effect in lung cancer [11]. More recently, we have observed that FZKA decoction inhibits the growth of NSCLC cells through phosphatidylinositol-3-kinase (PI3-K)/protein kinase B (Akt)-mediated inhibition of Nuclear factor- $\kappa \mathrm{B}$ (NF$\kappa \mathrm{B})$ subunit p65, followed by reducing expression of cell surface-associated mucin-1 (MUC1). More importantly, the combination of FZKA decoction and gefitinib, an epidermal growth factor receptor tyrosine kinase inhibitor (EGFR-TKI), has a synergistic effect on NSCLC cells. The in vitro and in vivo studies have provided a potential novel mechanism by which the FZKA decoction enhances the growth inhibition of gefitinib in gefitinib-resistant NSCLC cells [12]. Herein, we provided more evidences to demonstrate the proapoptotic effects of FZKA in lung cancer cells.

Caspase proteins, a group of cysteine proteases, have been well defined as key drivers in the process of cell apoptosis. Study reported that diallyl trisulfide (DATS), a constituent of processed garlic, could induce apoptosis of prostate cancer cell through enhancing the activities of caspase- 3 and caspase-9 proteins, which was inhibited in the presence of caspase-3- or caspase-9-specific inhibitors, Z-VAD-FMK and Z-LEHD-FMK [13]. Another group also showed that artesunate, a derivative of artemisinin extracted from Artemisia annua, induced apoptosis through caspase-dependent mitochondrial pathway [14], suggesting the critical role of the caspase pathway in this process. The Bcl-2 protein family are large apoptosis regulatory proteins that modulate the mitochondrial pathway [15]. The increase of $\mathrm{Bcl}-2$ protein family member Bax leads to the release of cytochrome $\mathrm{C}$ and other proapoptotic molecules from intermembranous space to cytosol, resulting in activation of downstream caspases [16]. Among those, caspase- 3 is a frequently activated death protease, which cleaves poly(ADP-ribose) polymerase (PARP), a DNA repair enzyme [17]. Transcription factor signal transducer and activator of transcription 3 (STAT3) has been shown to be closely associated with not only growth but also apoptosis in cancer. STAT3 regulated cell survival by inducing $\mathrm{Bcl}-2$ and $\mathrm{Bcl}-\mathrm{XL}$ to repress apoptosis; thus degradation and inhibition of STAT3 increased apoptosis in several cancer cells $[18,19]$. Nevertheless, the detailed mechanism
TABLE 1: Components of "Fuzheng Kang-Ai" (FZKA) decoction.

\begin{tabular}{lcc}
\hline Chinese name & Common name & Weight (g) \\
\hline Tai Zi Shen & $\begin{array}{c}\text { Radix Pseudostellariae } \\
\text { Rhizoma Atractylodis } \\
\text { Bai Zhu }\end{array}$ & 30 \\
Huangqi & Milkvetch Root & 15 \\
Baihuasheshecao & Hedyotis diffusa & 30 \\
Long Kui & Solanum nigrum & 30 \\
Shi Jian Chuan & Chinese Sage Herb & 30 \\
Shancigu & Indian Iphigenia Bulb & 30 \\
Yi Yi Ren & Coix seed & 30 \\
Bayuezha & Akebia trifoliata Koidz. & 30 \\
Shepaole & Snake bubble ilicifolius & 30 \\
Ezhu & Curcuma zedoaria & 15 \\
Gan Cao & Licorice & 10 \\
\hline
\end{tabular}

underlying those complicated regulation axes, especially how those molecules modulate cell apoptosis and control lung cancer cell growth, still remains to be elucidated. In the current study, we performed experiments to understand the molecular mechanism by which FZKA induced apoptosis in lung cancer cells.

\section{Materials and Methods}

2.1. Fuzheng Kang-Ai Decoction (FZKA Decoction). Decoction of FZKA, a Chinese herbal medicine (CHM) prescribed at the clinic, obtained from Guangdong Kangmei pharmaceutical Company, Ltd. (Guangdong, China), has been used to treat NSCLC in Guangdong Provincial Hospital of Chinese Medicine for more than 10 years. Table 1 listed the components of this decoction and the FZKA decoction has been reported previously [10]. The batch to batch consistency studies (the chromatograms in FZKA decoction) using highperformance liquid chromatography (HPLC) analysis and chemical profiling of main constituents in FZKA decoction using ultra-high pressure liquid chromatography coupled with LTQ Orbitrap mass spectrometry have been reported previously [11]. All of the components from this prescription were soaked for $30 \mathrm{~min}$ before decoction. The concentration liquid was finally spray-dried into particles by Guangdong One Pharmaceutical Co., Ltd. For in vitro experiments, the granules were dissolved in RPMI-1640 medium to a final concentration of $20 \mathrm{mg} / \mathrm{mL}$ and centrifuged at $14,000 \mathrm{rpm}$ for $10 \mathrm{~min}$; the supernatant was then filtered with $0.22 \mu \mathrm{m}$ filter before use and the $\mathrm{PH}$ value of the cultured cells with media was adjusted to 7.2-7.4 after FZKA addition.

2.2. Chemicals and Cell Culture. Monoclonal antibodies specific of caspase-3, PAPR, caspase-9, Bcl-2, myeloid cell leukemia-1 (Mcl-1), Bax, Jun activation domain-binding protein 1 (Jab1), total STAT3 and the phosphor forms, and p21 were purchased from Cell Signaling Technology, Inc. (Beverly, MA, USA). Caspase- 3 and caspase- 9 activity assay 
kits were ordered from Abcam (Cambridge, MA, USA). Lipofectamine 3000 reagent was purchased from Life Technologies (AB \& Invitrogen) (Carlsbad, CA, USA). STAT3 overexpression vector was obtained from OriGene Technologies, Inc. (Rockville, MD, USA). Dimethyl sulfoxide (DMSO) was purchased from Sigma-Aldrich Co. (St. Louis, MO, USA). NSCLC cells A549 were obtained from the Cell Line Bank at the Laboratory Animal Center of Sun Yat-sen University (Guangzhou, China) and PC9 and H1650 were obtained from the Chinese Academy of Sciences Cell Bank of Type Culture Collection (Shanghai, China). All cells were grown at $37^{\circ} \mathrm{C}$ in a humidified $5 \% \mathrm{CO}_{2}$ and $95 \%$ air and cultured in RPMI-1640 medium (Life Technologies, Carlsbad, CA, USA) containing $10 \%$ FBS (Gibco, USA) and $0.5 \%$ penicillinstreptomycin sulfate (Invitrogen Life Technologies, Carlsbad, CA, USA). Cells were counted using the automated cell counter star (Inno-Alliance Biotech Inc., Denver, CO, USA).

2.3. High-Performance Liquid Chromatography (HPLC) Anal$y$ sis. The initial batch to batch consistency study was performed using HPLC. Briefly, the samples solutions were put into the HPLC system $(250 \times 4.6 \mathrm{~mm}, 5 \mu \mathrm{m}$, ACE, Scotland $)$. The mobile phase consisted of deionized water with $0.1 \%$ formic acid (A) and acetonitrile with $0.1 \%$ formic acid (B). The gradient elution program was as follows: $5 \% \mathrm{~B}$ at $0-5 \mathrm{~min}$, $5-20 \%$ B at $5-10 \mathrm{~min}, 20-40 \% \mathrm{~B}$ at $10-15 \mathrm{~min}, 40-95 \% \mathrm{~B}$ at $15-40 \mathrm{~min}$, and $95-100 \% \mathrm{~B}$ at $40-45 \mathrm{~min}$. The flow rate was $1.0 \mathrm{~mL} / \mathrm{min}$, and the detection wavelength was set at $280 \mathrm{~nm}$. The injection volume was $10 \mu \mathrm{L}$ and the column temperature was maintained at $30^{\circ} \mathrm{C}$.

2.4. Flow Cytometry Analysis. Cell apoptosis was analyzed by Annexin V-FITC/PI Apoptosis Detection Kit according to the manufacturer's protocol (Sigma-Aldrich Co., St. Louis, MO). Briefly, cells (H1650, A549, and PC9) were seeded in 6 -well plates. After $24 \mathrm{~h}$ of culture, cells were treated with increased doses of FZKA and then incubated at $37^{\circ} \mathrm{C}$ for $24 \mathrm{~h}$. Afterwards, cells were collected, centrifuged for $5 \mathrm{~min}$ at $1500 \mathrm{rpm}$, and resuspended in 1x binding buffer. Finally, $5 \mu \mathrm{L}$ Annexin V-FITC and $5 \mu \mathrm{L}$ PI were added to the cells at room temperature for $15 \mathrm{~min}$. The cells were then analyzed using flow cytometer (Beckman FC 500, Beckman Coulter, Inc., CA, USA).

2.5. Caspase-3/9 Activity Assay. Caspase-3/9 activities were measured using caspase-3/9 activity assay kit according to manufacturer's protocol (Cell Signaling Technology, Inc., Beverly, MA, USA). In brief, lung cancer cells treated with FZKA were harvested and lysed in lysis buffer $\left(4^{\circ} \mathrm{C}\right.$ for $30 \mathrm{~min})$. Equal amounts of formulations $(100 \mu \mathrm{L})$ were loaded onto a 96-well microplate and incubated at $37^{\circ} \mathrm{C}$ for $120 \mathrm{~min}$ with reaction buffer and the liberated DEVD-p-NA substrate. Afterwards, the caspase-3/9 activity was measured using the microplate reader at a wavelength of $405 \mathrm{~nm}$ and the caspase activities were expressed as percentage of enzyme activity compared to that in the control (untreated cells).
2.6. Western Blot Analysis. Briefly, the cells were harvested, washed, and lysed with 1x RAPI buffer. Protein concentration was determined by the Thermo BCA protein assay kit. Equal amounts of protein from cell lysates were solubilized in $5 \mathrm{x}$ SDS sample buffer and separated on $8-10 \%$ SDS polyacrylamide gels and transferred onto polyvinylidene fluoride membranes. Membranes were blocked with 5\% nonfat milk in TBST and incubated with primary antibodies against caspase-3, PAPR, caspase-9, Bcl-2, Mcl-1, Bax, total STAT3 and the phosphor form, Jab1, and p21 proteins at $4^{\circ} \mathrm{C}$ overnight. Afterwards, the membranes were washed and incubated with a secondary antibody against rabbit IgG for $1 \mathrm{~h}$, followed by washing and transferring into ECL solution (Millipore, Darmstadt, Germany), and scanned under the Bio-Rad ChemiDoc XRS+ chemiluminescence imaging system (Bio-Rad, Hercules, CA, USA). The results were measured by ImageJ software.

2.7. Transient Transfection Assays. The cells were seeded in 6well plates and reached to $50-60 \%$ confluence. The control, siRNA, and STAT3 overexpression vectors were obtained from OriGene Technologies, Inc. (Rockville, MD, USA). For each well, $2-4 \mu \mathrm{g}$ of STAT3 plasmid DNA constructs or 10-60 nM STAT3 siRNA was transfected into the cells using Lipofectamine 3000 reagent (Life Technologies, Carlsbad, CA, USA) for $24 \mathrm{~h}$ based on the instruction from the provider, followed by treatment with FZKA for an additional $24 \mathrm{~h}$ for all other experiments.

2.8. Statistical Analysis. Statistical analysis was performed using the SPSS statistical software. Statistical evaluation for data analysis used Student's $t$-test when there were only two groups (two-sided) and differences between groups were assessed by one-way ANOVA. All data are reported as means \pm SD. Differences between groups were considered statistically significant when $P \leq 0.05$.

\section{Results}

3.1. Different Drinks of FZKA Decoction Have Similar Patterns. We performed HPLC (high-performance liquid chromatography) to identify the main components in the different drinks of FZKA decoction. Our results showed that HPLC chromatograms in four drinks of FZKA decoction have similar patterns, revealing that the FZKA decoction has a good stability (Figure 1).

3.2. FZKA Induces Lung Cancer Cell Apoptosis. Our previous studies have shown that FZKA decoction inhibited lung cancer cell growth through multiple mechanisms [11, 12]. We then explored the potential mechanism by which FZKA affected apoptosis in NSCLC cells. Flow cytometry of cell apoptosis was performed when treating NSCLC cells (H1650, A549, and PC9) with different doses of FZKA for $24 \mathrm{~h}$. Our results showed that FZKA significantly induced the apoptosis in NSCLC cells (more than 50\% when treated with $1.5 \mathrm{mg} / \mathrm{mL}$ FZKA) in a dose-dependent manner as shown in the right (A2 and A4) quadrants of the histograms, which 


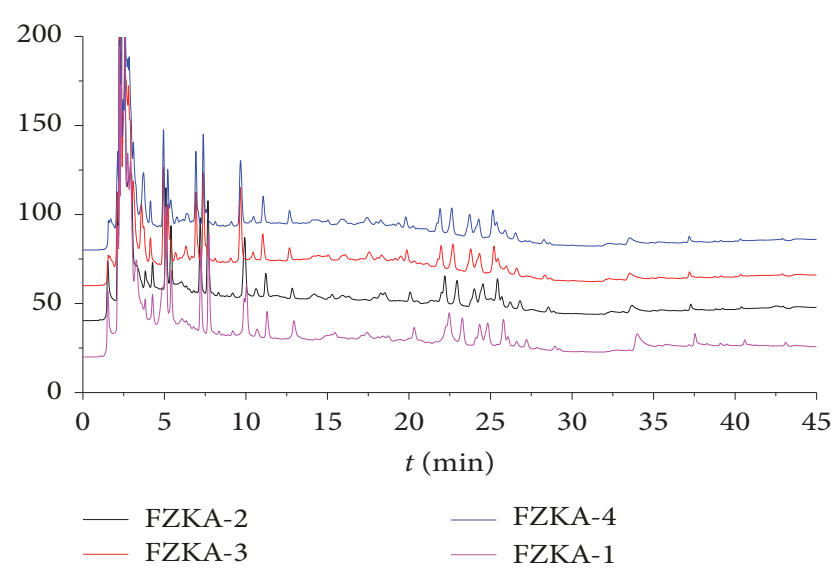

FIGURE 1: HPLC chromatograms in different drinks of FZKA decoction have similar patterns. The water extraction of the compound prescriptions of the different groups of the FZKA decoction was qualitatively analyzed by HPLC method as described in Section 2. Conditions: column: $\mathrm{C}_{18}$ column $(250 \times 4.6 \mathrm{~mm}, 5 \mu \mathrm{m})$; rate: $1.0 \mathrm{~mL} / \mathrm{min}$; column temperature: $30^{\circ} \mathrm{C}$; injection volume: $10 \mu \mathrm{L}$. Four batches of FZKA decoction water extracts including a mixture of three different batches (FZKA 1-4) are presented.

were counted as apoptotic cells detected by the Annexin VFITC/PI Apoptosis Detection Kit. After $24 \mathrm{~h}$ of treatment, the FZKA-induced apoptotic rate was greater than that in the nontreated control cells (Figures 2(a)-2(c)).

3.3. FZKA-Stimulated Activation of Caspase-3/9 Contributes to the Induction of Apoptosis in Human Lung Cancer Cells. To identify the relevant targets of FZKA-induced apoptosis, we started to examine the effect of FZKA on the activation of caspases. We observed that FZKA increased the activation of caspase- 3 in a dose-dependent fashion in H1650 and A549 cells (Figure 3(a)). In line with this, the Western blot experiments also showed activation of caspase- 3 by inducing cleaved-caspase-3 (c-caspase-3) protein in H1650 and A549 cells (Figures 3(b) and 3(c)). Furthermore, we then tested whether the induction of apoptosis by FZKA is associated with extrinsic or intrinsic apoptosis pathway. We found that caspase-9, a key component of intrinsic apoptosis pathway, was significantly activated by the FZKA treatment as shown by cleaved-caspase-9 (c-caspase-9) protein levels in H1650 and A549 cells, suggesting that the apoptotic effect of FZKA is mediated at least in part by the extrinsic apoptosis pathway (Figures 3(d) and 3(e)).

\subsection{Bcl-2 Family Is Involved in the FZKA-Induced Lung Cancer} Cell Apoptosis. The apoptosis signaling can be initiated either at the cell surface through a death receptor-induced signaling pathway or within the cell via the release of proapoptotic molecules, such as Bcl-2 family proteins. Caspases are linked to Bcl-2 family which is the key regulator of apoptosis in cancer [20]. To further clarify the molecular mechanisms underlying FZKA-induced apoptosis in lung cancer cells, the expressions of Bcl-2 family members including Bcl-2, Mcl1, and Bax in H1650 and A549 cells treated with FZKA were examined. The results demonstrated that the expression of Bcl-2 and Mcl-1 (two antiapoptotic proteins) was decreased, whereas the expression of Bax (proapoptotic protein) was increased in a dose-dependent manner (Figures 4(a) and 4(b).). The above results suggested that the apoptosis induced by FZKA was mediated through mitochondria-dependent pathway as well as changes in the protein expressions of Bcl-2 families.

3.5. STAT3/Jab1/p27 Pathways Play a Role in the Process of FZKA-Induced Lung Cancer Cell Apoptosis. STAT3 has been reported to modulate the expression of genes involved in antiapoptosis, such as Bcl-2 and Mcl-1. We then tested the expression of STAT3 by FZKA treatment. Our results showed that STAT3 expression was decreased by FZKA treatment in dose-dependent manner, and the phosphorylation of STAT3 was also inhibited by FZKA in a time-dependent manner (Figure 5(a)). Jab1/CSN5 (c-Jun activation domain-binding protein 1 , Jabl hereafter) was originally identified as a cJun coactivator and subsequently discovered to be one of downstream molecules of STAT3, which functions as an oncoprotein in cancers [21]. In the present study, Jabl was found to be downregulated by FZKA treatment (Figure 5(b)). On the contrary, p27, a cell cycle inhibitor and one of the targets of Jabl [22], was unregulated by FZKA in H1650 and A549 cells in a dose-dependent manner (Figure 5(c)). The above data indicated that the STAT3/Jab1/p27 pathways might be involved in the FZKA-induced apoptosis in lung cancer cells.

3.6. Activation of Caspase-3 Mediates FZKA-Induced Apoptosis. To further interrogate whether caspases activation is required for the induction of apoptosis, we pretreated cells with the pan-caspase inhibitor Z-VAD-FMK at $50 \mu \mathrm{M}$ for $1 \mathrm{~h}$ before exposure of the cells to FZKA for an additional $24 \mathrm{~h}$. Our results showed that the percentages of cell apoptosis of the group pretreated with Z-VAD-FMK as detected by the Annexin V-FITC/PI Apoptosis Detection Kit described in Materials and Methods were much lower as compared to those in the control group without Z-VAD-FMK treatment in H1650 and A549 cells (Figures 6(a) and 6(b)). This data indicated that FZKA-induced cell apoptosis was at least in part through the activation of caspase-3 pathway.

3.7. STAT3 Knock-Down Enhances the Effect of FZKA on the Activities of Caspase-3, Caspase-9, and Bcl-2 Families. To clarify the important role of STAT3 in the apoptosis process of FZKA on lung cancer cells, we decreased the expression of STAT3 by STAT3 siRNA transfection (Figure 7(a)). Our results showed that the combination of FZKA treatment with STAT3 knock-down increased the activities of both caspase3 and caspase- 9 in lung cancer cells, compared to FZKA alone (Figures $7(\mathrm{~b})$ and $7(\mathrm{c})$ ). Moreover, the expressions of Bcl-2 family including Bcl-2, Mcl-1, and Bax were also enhanced by STAT3 knock-down with the combination by FZKA, compared to FZKA alone (Figures 7(d)-7(f)). These 

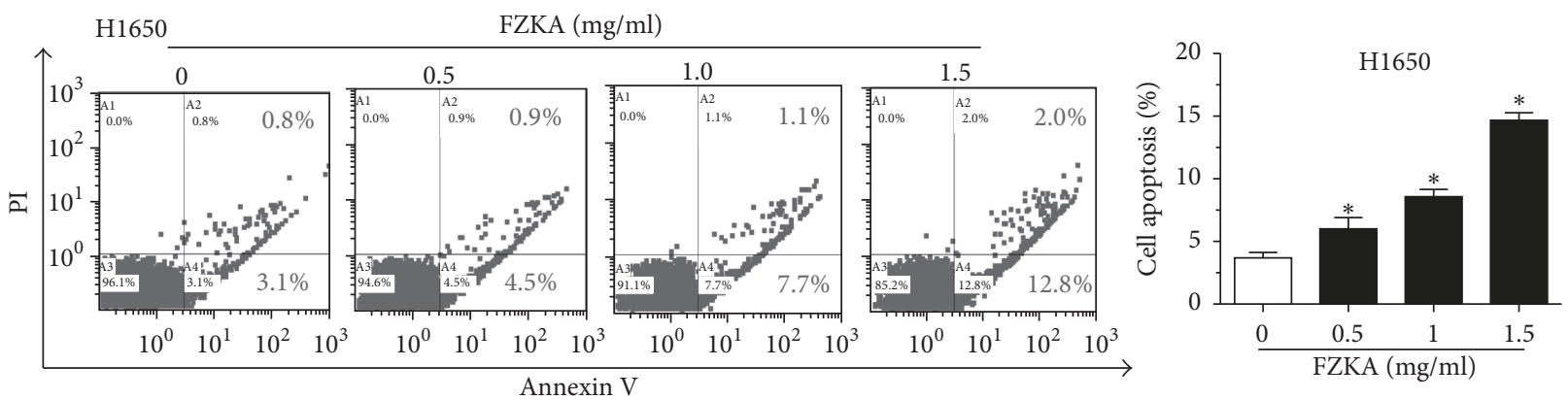

(a)
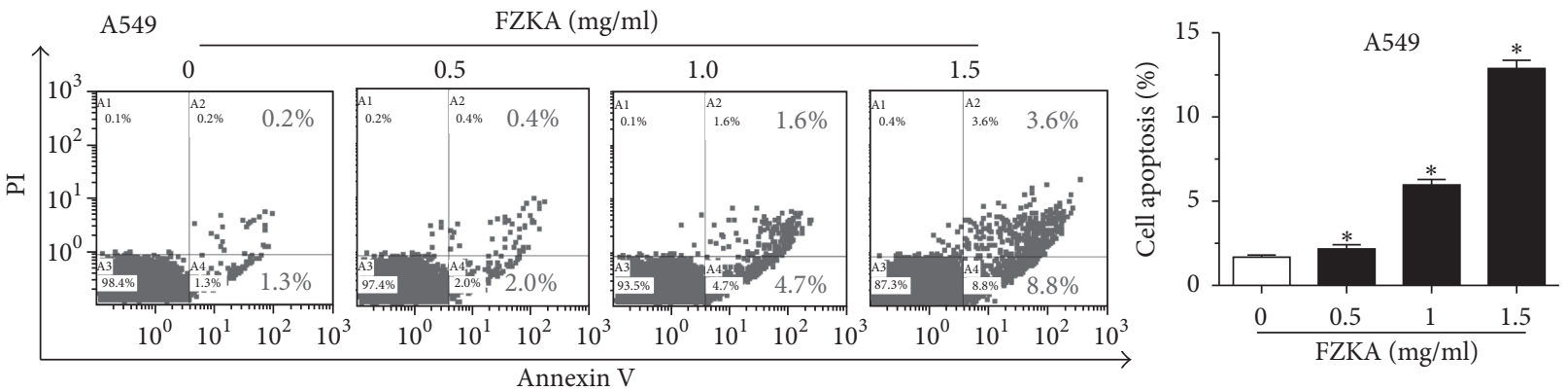

(b)
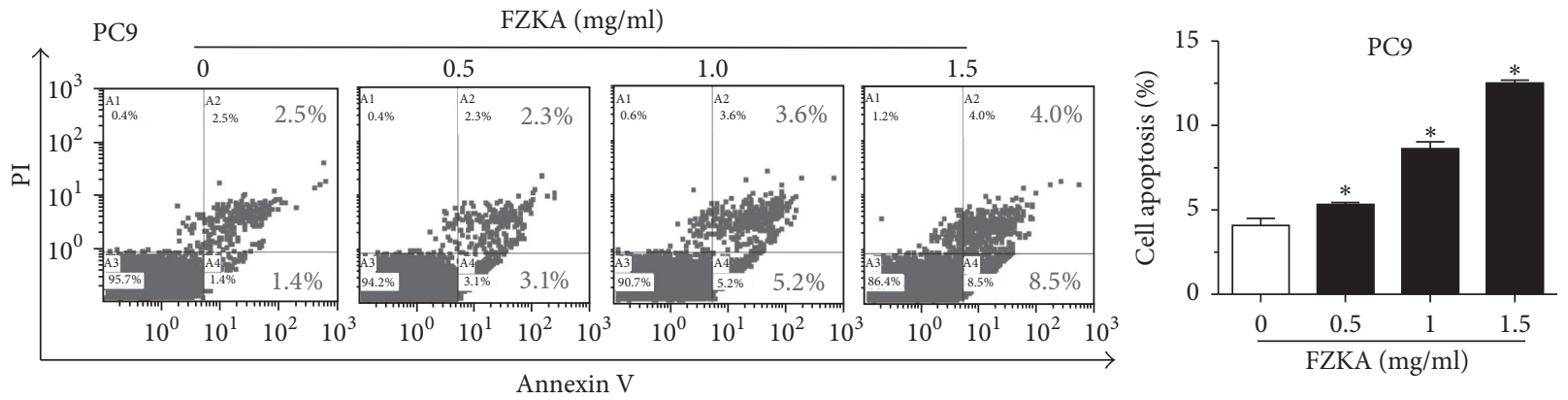

(c)

FIGURE 2: FZKA induces lung cancer cell apoptosis. (a-c) Lung cancer cells (H1650, A549, and PC9) were treated with increased concentrations of FZKA for $24 \mathrm{~h}$. Afterwards, cells were harvested for analysis of apoptosis using the Annexin V-FITC/PI Apoptosis Detection Kit as detailed in Materials and Methods. The A3 quadrant (annexin V-/PI-), A4 quadrant (annexin V+/PI-), and A2 quadrant (annexin V+/PI+) of the histograms indicated the percentage of normal cells, early apoptosis, and late apoptosis, respectively. Values in bar graphs were given as the mean \pm SD from three independent experiments performed in triplicate. * indicates significant difference as compared to the untreated control group $\left({ }^{*} \mathrm{P}<0.05\right)$.

results indicated the critical role of STAT3-mediation effect on FZKA-induced apoptosis in lung cancer cells.

\subsection{Overexpression of STAT3 Overcomes the Effect of FZKA} on the Activities of Caspase-3, Caspase-9, and Bcl-2 Families. To further clarify the functional relevance of those potential targets involved in the regulation of cell apoptosis by FZKA treatment, we then decipher the role of STAT3 in this process. Our data showed that exogenous expression of STAT3 overcame the FZKA-induced activities of caspase- 3 and caspase- 9 in H1650 and A549 cells (Figures 8(a) and 8(b)). In line with these results, we also observed that the decreased expression of $\mathrm{Bcl}-2$ and $\mathrm{Mcl}-2$ as well as the increased Bax protein expression by FZKA was blocked in cells overexpressing STAT3 exogenously (Figures 8(a) and 8(d)). Collectively, these above results implied that STAT3 might be an upstream molecule of Bcl-2 family affected by FZKA in this process.

\section{Discussion}

In the present study, we proposed to uncover the role and mechanisms by which FZKA decoction affects apoptosis in lung cancer cells. We found that FZKA exerted the cytotoxic effects via the induction of apoptosis in lung cancer cells. At present, there are two widely accepted classical pathways of cell apoptosis: mitochondrial pathway and death receptor 


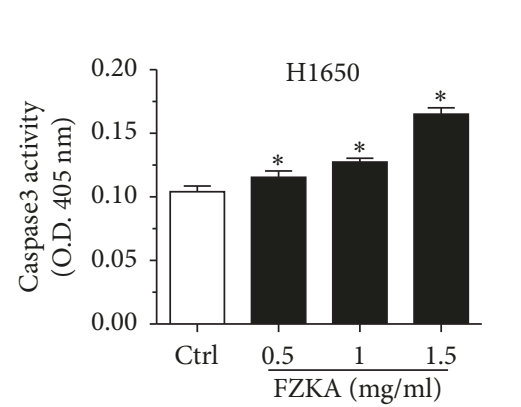

(a)

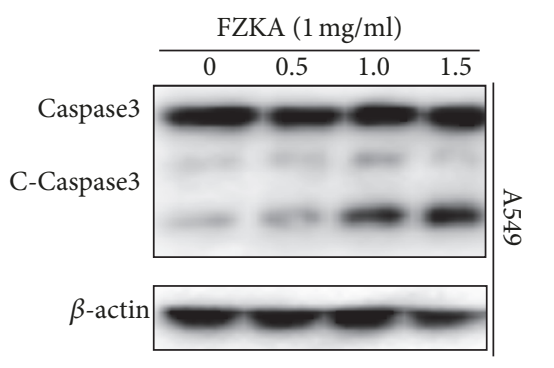

(c)

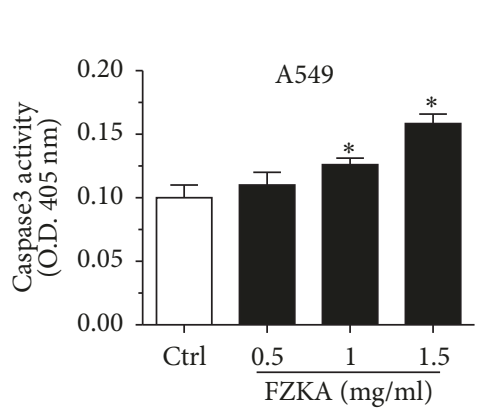

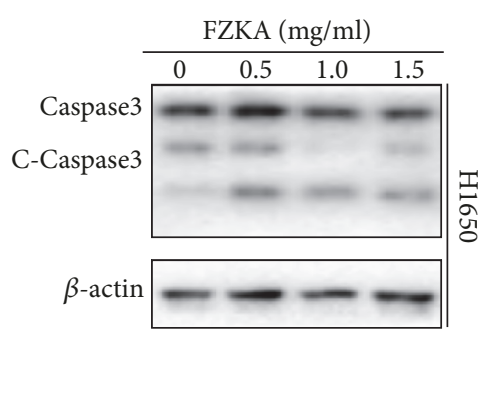

(b)
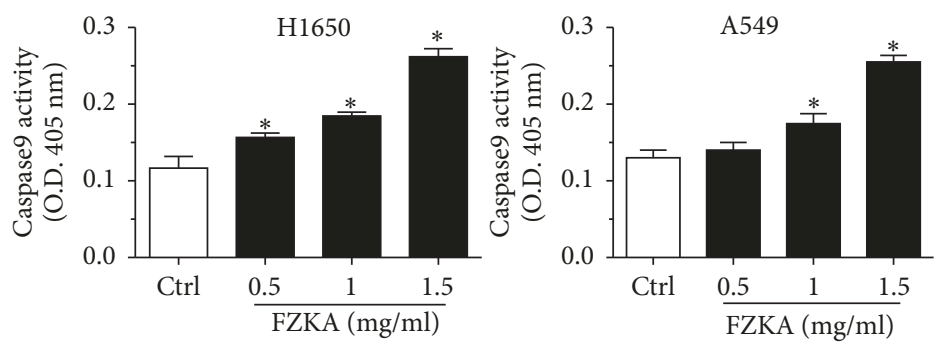

(d)

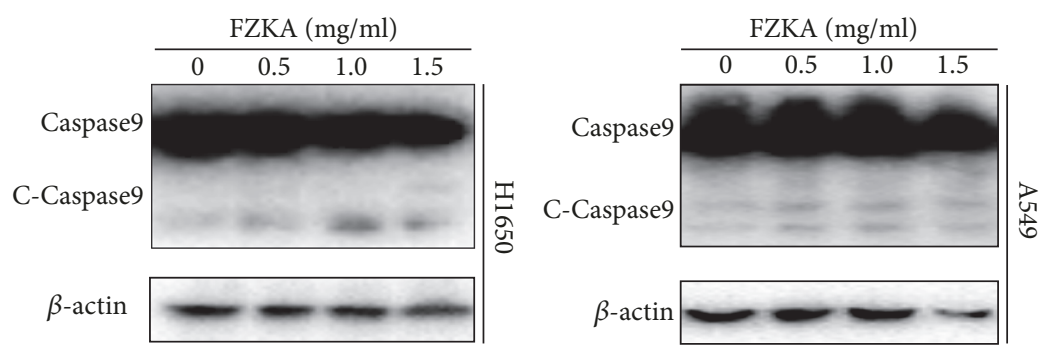

(e)

FIGURE 3: FZKA-stimulated activation of caspase-3/9 contributes to the induction of apoptosis in human lung cancer cells. (a) Caspase-3 activity was detected using caspase-3 activity assay kit in H1650 and A549 cells treated with FZKA as indicated doses for 24 h. Data represent means \pm SD of three independent experiments. * indicates significant difference as compared to the untreated control group $\left({ }^{*} P<0.05\right)$. $(b-c)$ The protein expression levels of caspase- 3 and c-caspase- 3 were detected by Western blot. $\beta$-Actin was used as an internal control. The results were measured by ImageJ software. (d) Caspase- 9 activity was detected using caspase- 9 activity assay in H1650 and A549 cells treated with indicated doses of FZKA for $24 \mathrm{~h}$. Data represent means \pm SD of three independent experiments. $*$ indicates significant difference as compared to the untreated control group $\left({ }^{*} P<0.05\right)$. (e) The protein expression levels of caspase- 9 and c-caspase- 9 were detected by Western blot. $\beta$-Actin was used as an internal control.

pathway $[23,24]$. Mitochondria play a key role in the process of cell apoptosis as they can regulate and participate in the whole process of tumor cell apoptosis [25]. During cell apoptosis, the apoptotic pathway is reflected in the aspects of modification of mitochondrial transmembrane voltage and increase of caspase activity induced by the openness of mitochondrial outer membrane permeability (MOMP) [26]. Our results showed that FZKA induced the cleavage of caspase- 9 and caspase-3 in lung cancer cells. When caspase- 3 was inhibited by its inhibitor Z-VAD-FMK, cell apoptosis induced by FZKA could be blocked. This data strongly suggested that the FZKA-induced apoptosis was through a mitochondrial pathway in a caspase-3-dependent manner.
It has been reported that Bax can transfer to mitochondrial outer membrane along cytoplasm and thus enhance the permeability of mitochondrial membrane. Therefore, when the level of Bax increases and transmembrane voltage steps down, proteins located in mitochondria such as cytochrome can be released so that a series of reactions are brought about and cell apoptosis occurs in tumor cells [26-28]. Another study showed that bufalin, a cardiotonic steroid, reduced the expressions of antiapoptotic protein $\mathrm{Bcl}-2$ and surviving and increased the proapoptotic protein Bax/Bcl-2 rate in several different cancer types [29]. Consistent with this, we demonstrated that FZKA induced expression of Bax, while it inhibited the expression of Bcl-2 and Mcl-1 from $\mathrm{Bcl}-2$ family. The data presented herein suggested that 

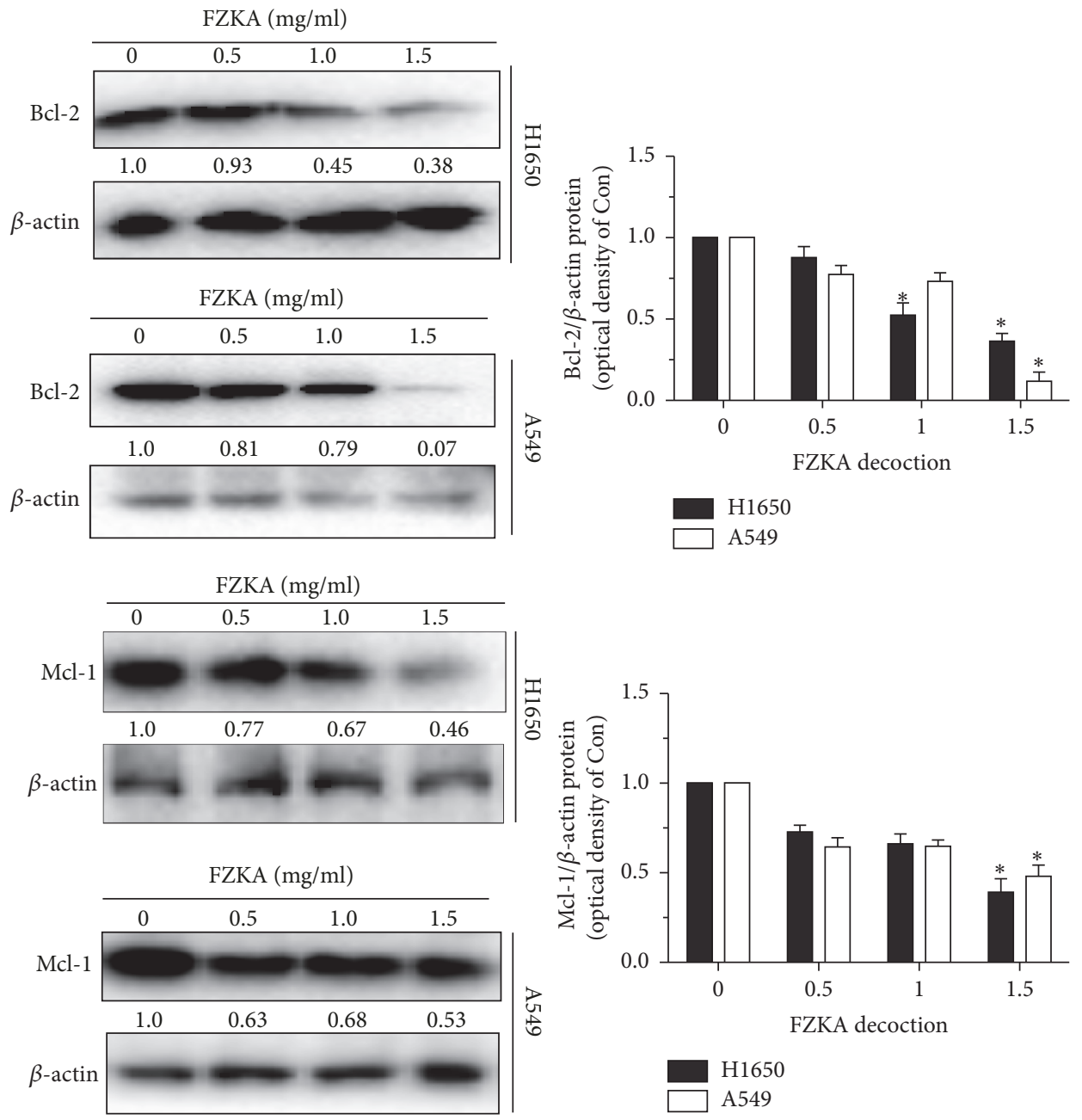

(a)
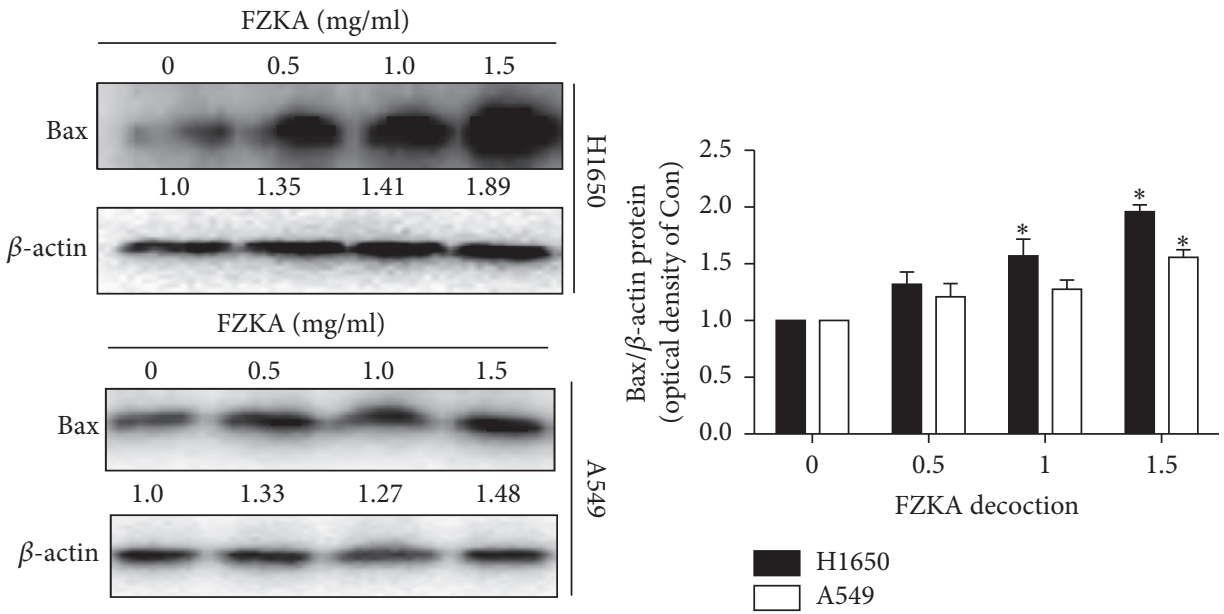

(b)

FIGURE 4: Bcl-2 family is involved in the FZKA-induced lung cancer cell apoptosis. (a-b) The protein expression levels of Bcl-2, Mcl-1, and Bax were detected by Western blot. $\beta$-Actin was used as an internal control. The results were measured by ImageJ software. Values in bar graphs were given as the mean \pm SD from three independent experiments. $*$ indicates significant difference as compared to the untreated control group $(P<0.05)$. 

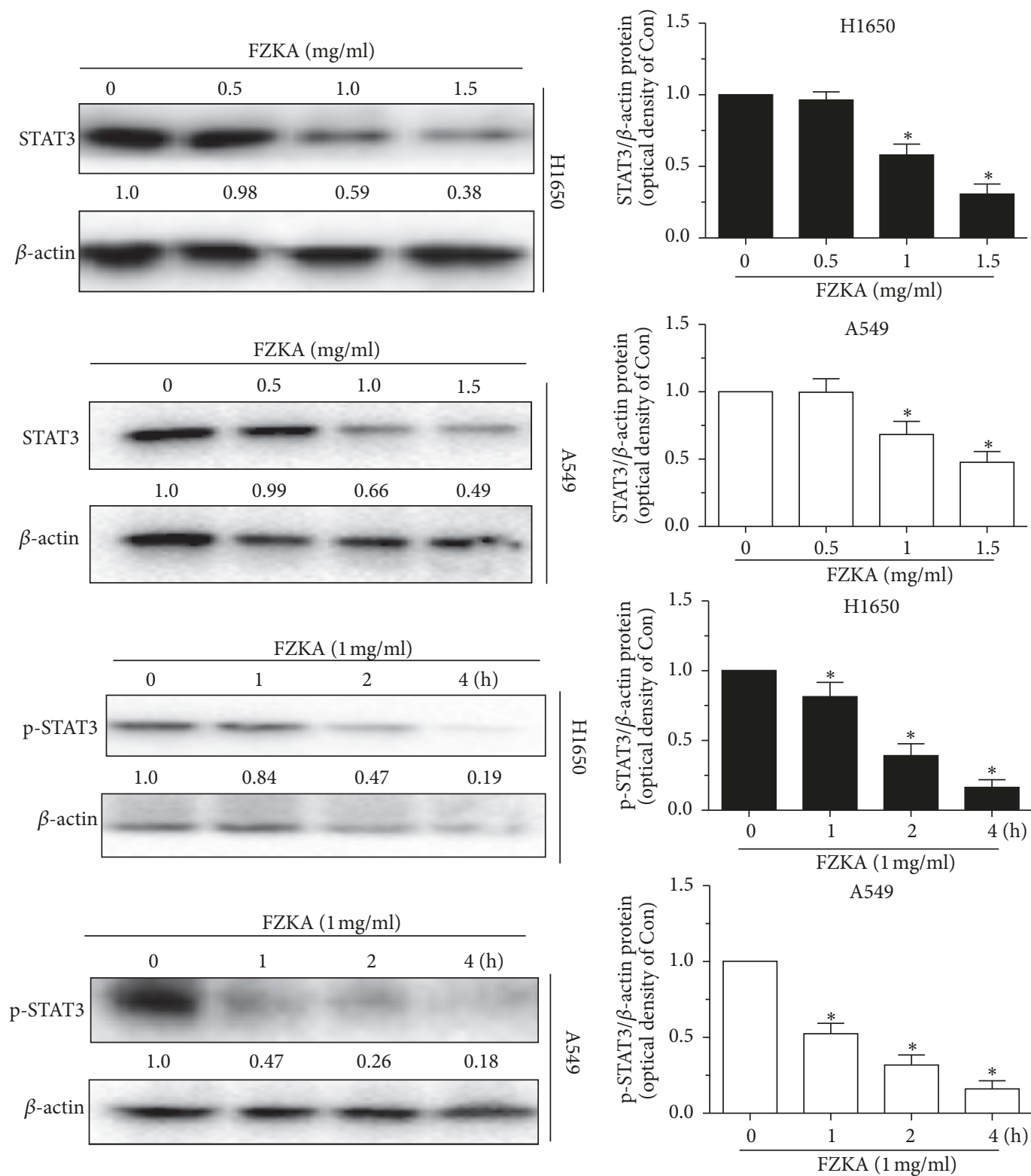

(a)
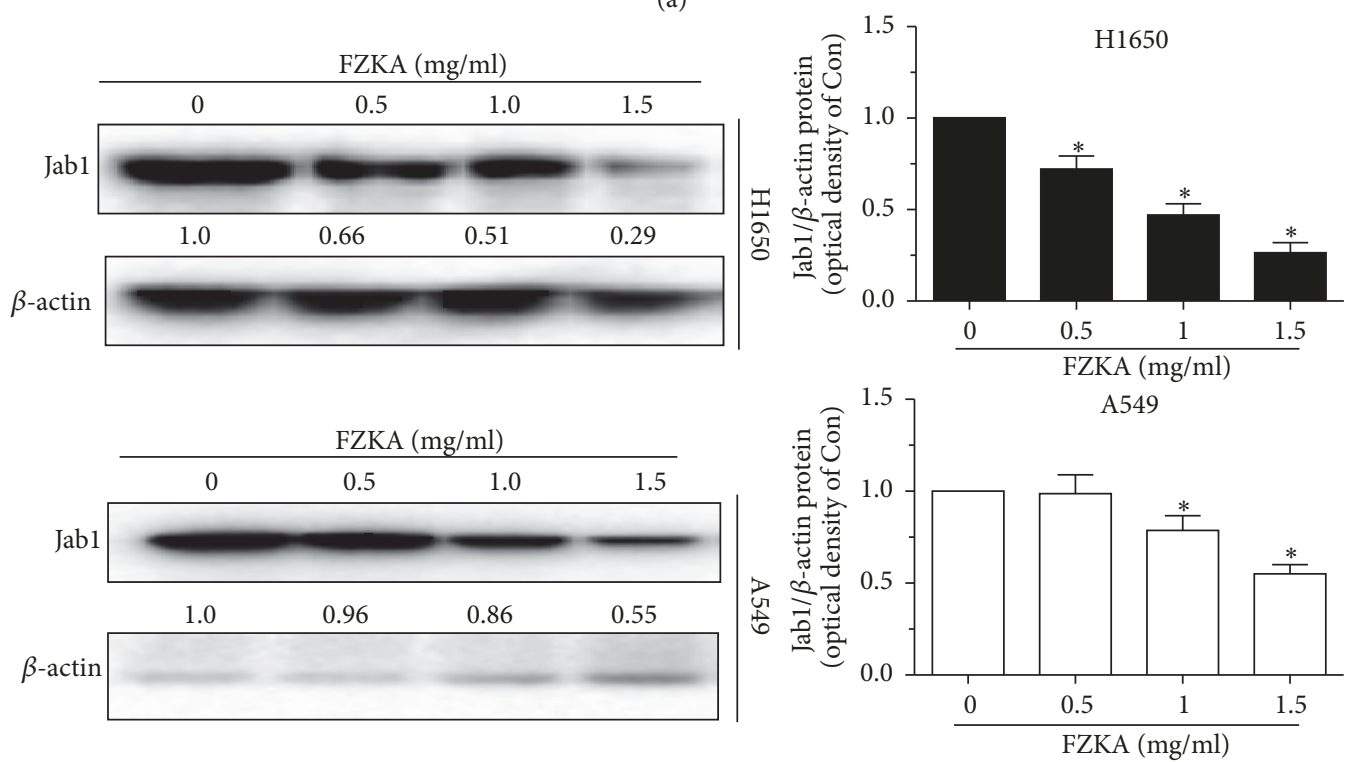

(b)

Figure 5: Continued. 

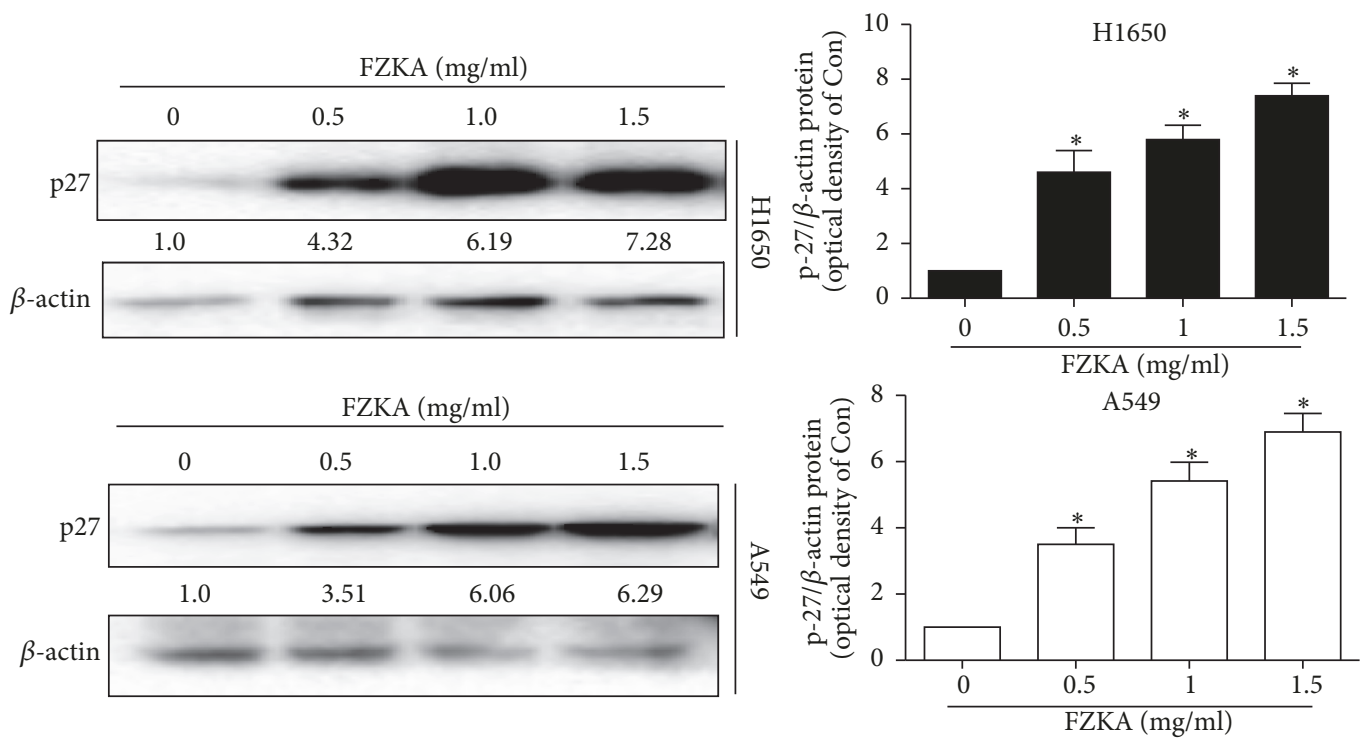

(c)

FIGURE 5: STAT3/Jab1/p27 pathways play a role in the process of FZKA-induced lung cancer cell apoptosis. (a-c) A549 and H1650 cells were treated with indicated doses of FZKA for up to $4 \mathrm{~h}$ and cell lysate was harvested, and the expressions of the phosphorylated or total protein of STAT3, Jab1, and p27 were measured by Western blot analysis using corresponding antibodies. $\beta$-Actin was used as an internal control. Data were measured by ImageJ software. Values in bar graphs were given as the mean \pm SD from three independent experiments. $*$ indicates significant difference as compared to that in the untreated control group $\left({ }^{*} P<0.05\right)$.

Bcl-2 family mediated the FZKA-induced cell apoptosis in a mitochondrion-dependent manner.

Moreover, FZKA induced lung cancer cell apoptosis significantly with concomitant induction of $\mathrm{p} 27$, reduction of Jabl protein expression, and phosphorylation of STAT3. Transcription factor STAT3 is often constitutively activated in various human cancers and controls the expression of multiple genes involved in tumor initiation, growth, progression, and apoptosis [30, 31]. Once activated, STAT3 undergoes phosphorylation-induced homodimerization, leading to nuclear translocation, DNA binding, and subsequent gene transcription. Regulation of STAT3 has been reported to modulate the expression of genes involved in cell apoptosis, such as Bcl-2 family [32]. Thus we reasoned that STAT3 regulated the expression of $\mathrm{Bcl}-2$ family in the FZKA-treated lung cancer cells. Our results demonstrated that exogenously overexpressed STAT3 abolished FZKAinduced apoptosis, implying the role of STAT3 expression in this process. Those findings provided evidence and suggested that STAT3/Bcl-2/caspase-3 signaling pathways were involved in the FZKA-induced apoptosis in NSCLC cells. On the other hand, Jab1, acting as a modulator of intracellular signaling and affecting cellular proliferation and apoptosis and a target of STAT3 [33, 34], also decreased in FZKA-treated NSCLC cells. Meanwhile, in the current study, FZKA-treated NSCLC cells showed an increase in protein expression of $\mathrm{p} 27$, a cyclin-dependent kinase (Cdk) inhibitor, which results in cell-cycle arrest [35]. This data indicated that STAT3/Jab1/p27 pathways might contribute to the FZKA-induced lung cancer cell apoptosis. Collectively, these above findings uncovered a novel mechanism by which FZKA decoction acted as a tumor suppressive compound and inhibited lung cancer cell growth. More experimental approaches are still required to further elucidate the molecular mechanism underlying this proapoptotic process by FZKA.

\section{Conclusions}

In our study, we investigated the effects of FZKA on the cell apoptosis in human lung cancer cells. Our results show that FZKA induces apoptosis of H1650 and A549 cells via inhibition of STAT3, followed by increasing protein expression of Bax, concomitantly decreasing $\mathrm{Bcl}-2$ and $\mathrm{Mcl}-1$ protein levels, and significantly activating caspase- 9 and caspase3. The overall effects of FZKA were significantly abrogated in cells transfected with exogenously overexpressed STAT3. Taken together, these results uncover an additional mechanism by which FZKA controls human lung cancer cell growth.

\section{Conflicts of Interest}

The authors declare that there are no conflicts of interest regarding the publication of this paper.

\section{Authors' Contributions}

Swei Sunny Hann (hann2012@outlook.com) and Wanyin Wu (wwanyin@126.com) were responsible for the experiment design and drafting the manuscript. Sumei Wang 

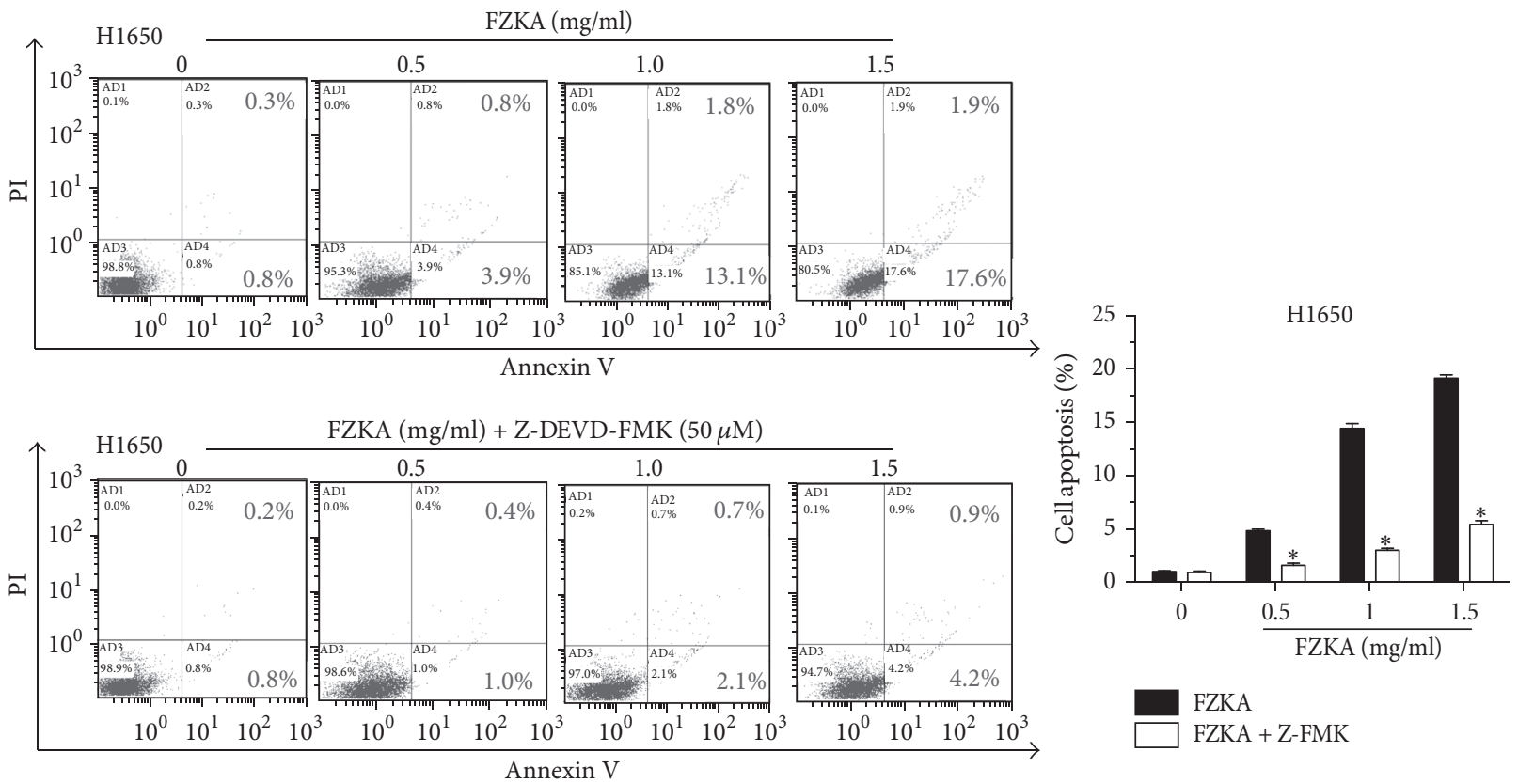

FZKA

FZKA + Z-FMK

(a)
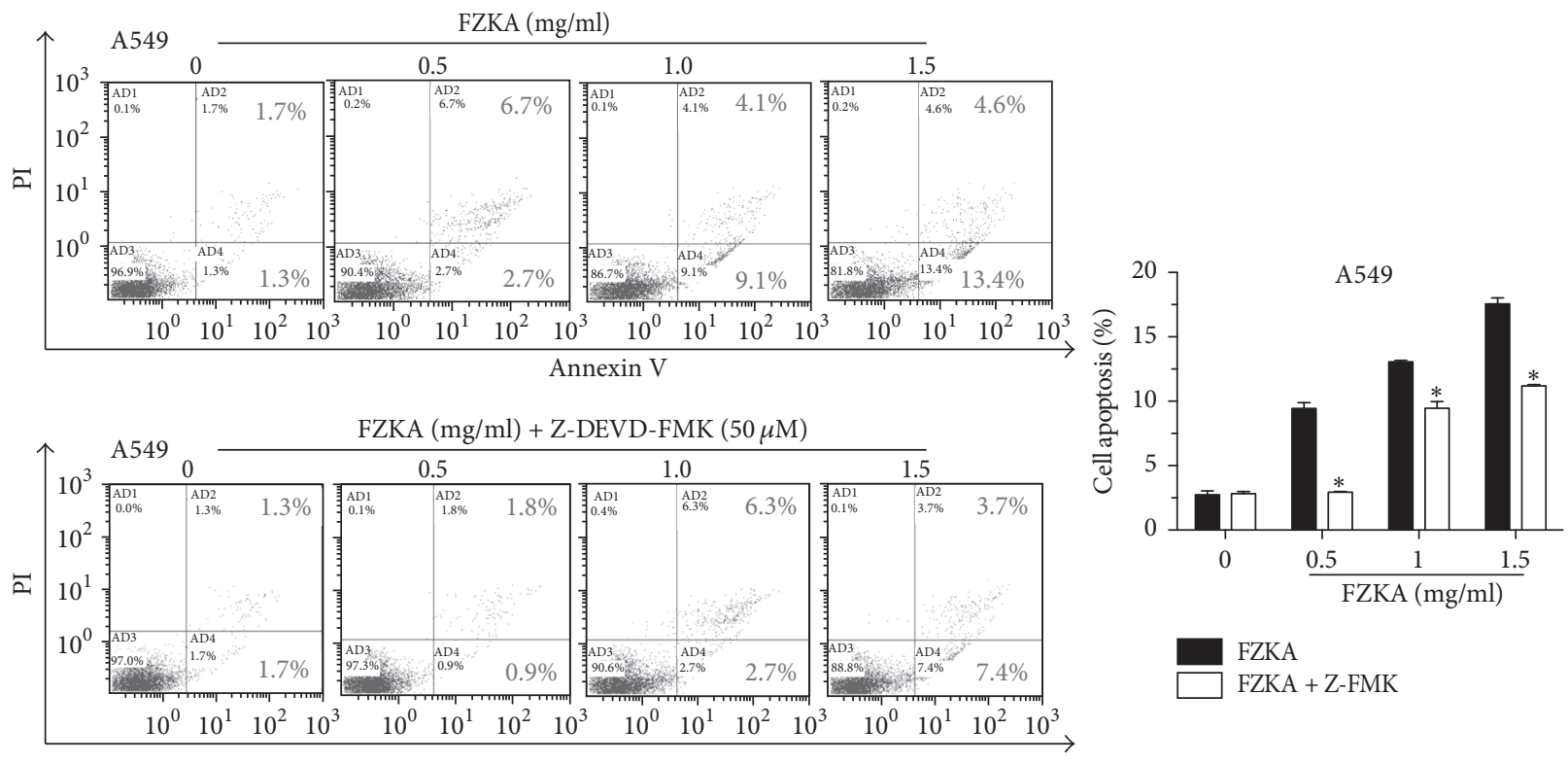

(b)

Figure 6: Activation of caspase-3 mediates FZKA-induced apoptosis. (a-b) H1650 and A549 cells were seeded into 6-well plates and treated with increased doses of FZKA or the pan-caspase inhibitor Z-VAD-FMK at $50 \mu \mathrm{M}$ for $1 \mathrm{~h}$ before exposing the cells to FZKA for an additional $24 \mathrm{~h}$. Afterwards, cells were harvested for analysis of apoptosis using the Annexin V-FITC/PI Apoptosis Detection Kit as detailed in Materials and Methods. The AB3 quadrant (annexin V-/PI-), AB4 quadrant (annexin V+/PI-), and AB2 quadrant (annexin V+/PI+) of the histograms indicated the percentage of normal cells, early apoptosis, and late apoptosis, respectively. Values in bar graphs were given as the mean $\pm \mathrm{SD}$ from three independent experiments performed in triplicate. $*$ indicates significant difference as compared to the untreated control group $(P<0.05)$. 


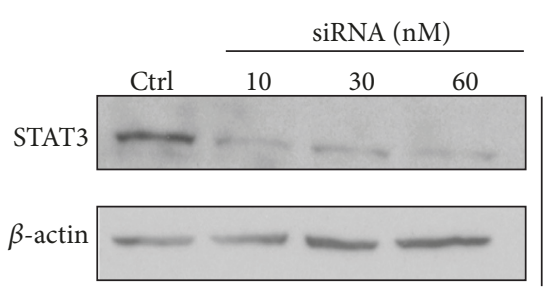

(a)

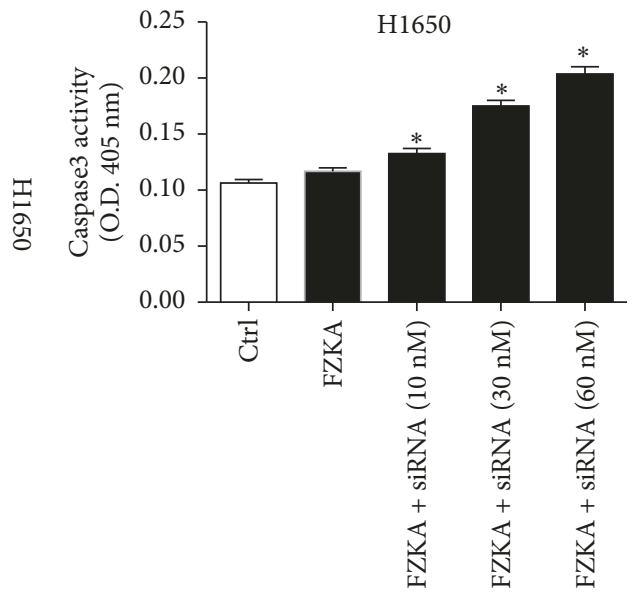

(b)

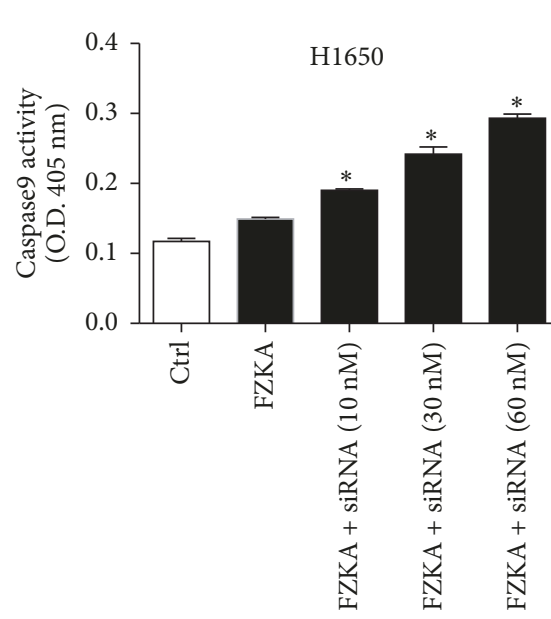

(c)

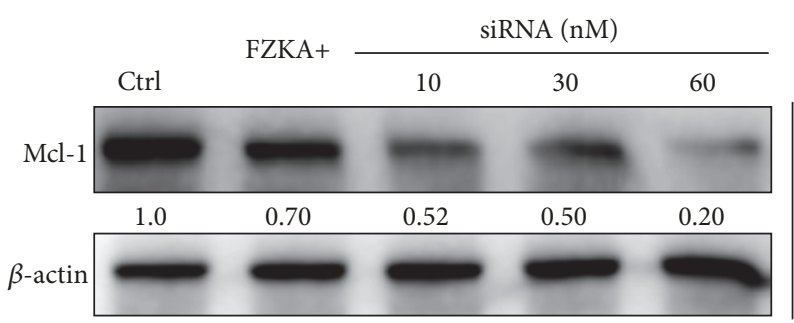

(e)

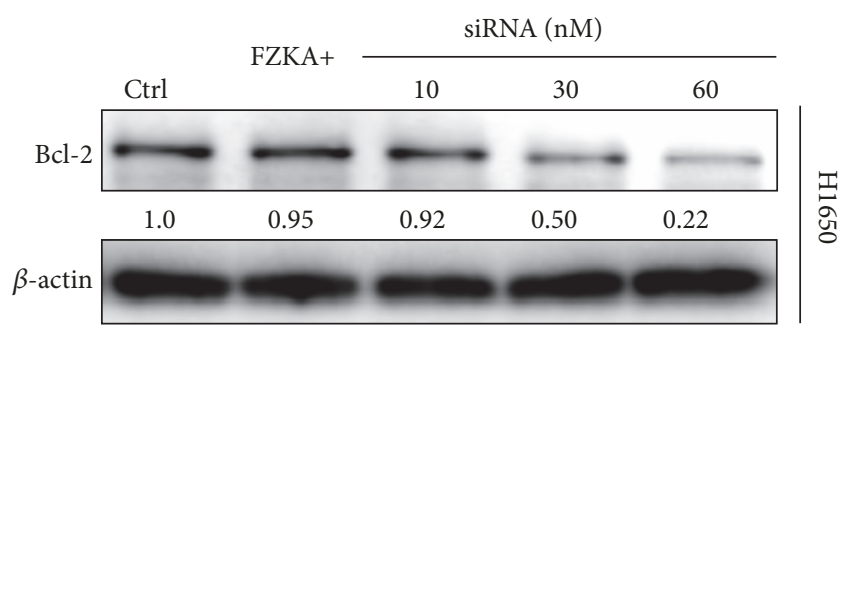

(d)

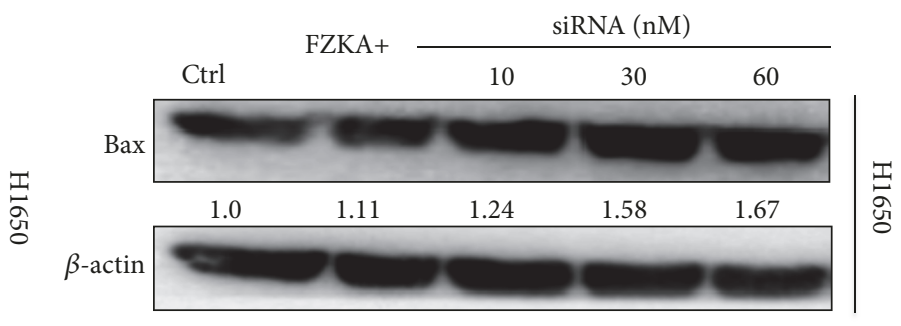

(f)

FIGURE 7: STAT3 knock-down enhanced the effect of FZKA on the activities of caspase-3, caspase-9, and Bcl-2 families. (a) STAT3 siRNA and control were transfected to H1650 cells and STAT3 expression was decreased in a dose-dependent manner. (b-c) H1650 cells were transfected with control or STAT3 siRNA for $24 \mathrm{~h}$, followed by exposure of the cells to FZKA for an additional $24 \mathrm{~h}$. Afterwards, caspase- 3 and caspase9 activities were detected using caspase-3/9 activity assay as described in Materials and Methods. Data represent means \pm SD of three independent experiments. * indicates significant difference as compared to the untreated control group $(P<0.05)$. (d-f) H1650 cells were transfected with control or STAT3 siRNA for $24 \mathrm{~h}$, followed by exposure of the cells to FZKA for an additional $24 \mathrm{~h}$. The protein expression levels of Bcl-2, Mcl-1, and Bax were detected by Western blot. $\beta$-Actin was used as an internal control.

(wangsumei198708@163.com) was involved in performing the majority of the experiments and writing the manuscript. Shunqin Long (thingkingling@126.com) and Shujing Xiao (shujing-020@163.com) provided some useful suggestions and reagents. All authors read and approved the final manuscript.

\section{Acknowledgments}

This work was supported by grants from the Doctoral Research Project of Guangdong Natural Science Foundation of China (2017A030310326), the Guangdong Science and Technology Plan Project (2016A020226035 and 


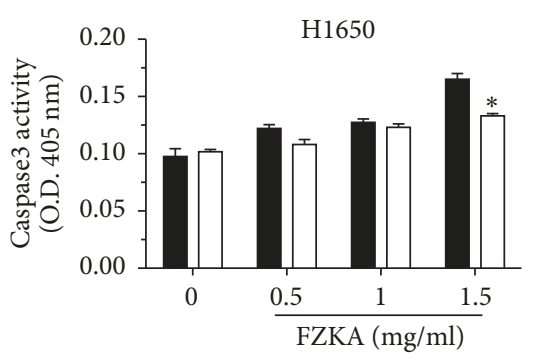

FZKA

FZKA + STAT3 plasmid

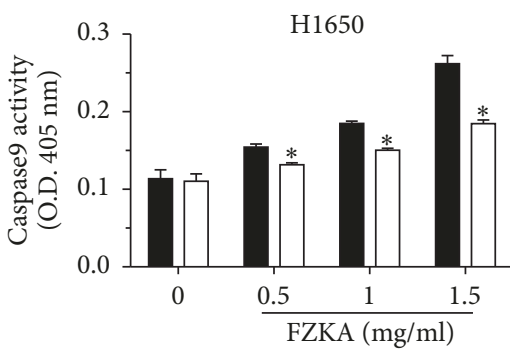

FZKA

FZKA + STAT3 plasmid

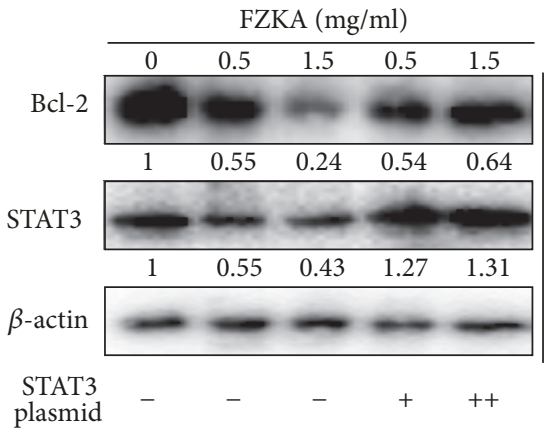

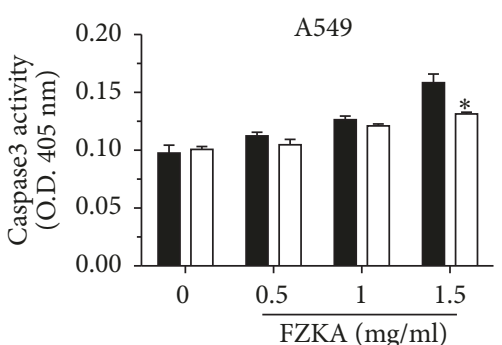

FZKA

FZKA + STAT3 plasmid

(a)

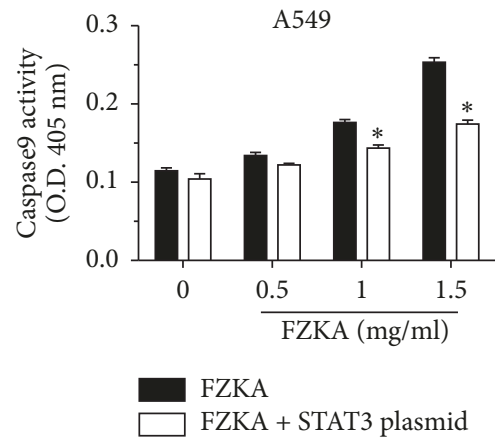

(b)

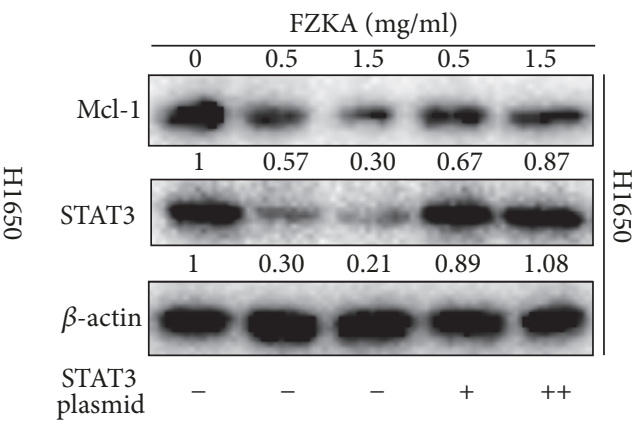

(c)

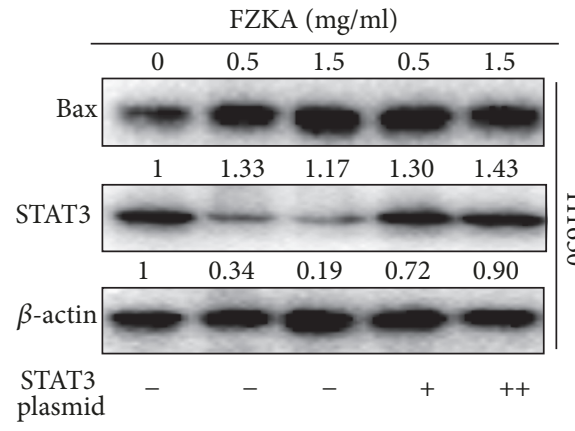

(d)

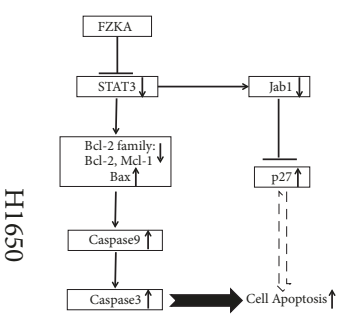

Human lung cancer cells

$\rightarrow$ Stimulation

$\rightarrow$ Inhibition

(e)

FIGURE 8: Overexpression of STAT3 overcame the effect of FZKA on the activities of caspase-3, caspase-9, and Bcl-2 families. (a-b) H1650 and A549 were transfected with control or STAT3 overexpression plasmids for $24 \mathrm{~h}$, followed by exposure of the cells to FZKA for an additional $24 \mathrm{~h}$. Afterwards, caspase-3 and caspase- 9 activities were detected using caspase-3/9 activity assay as described in Materials and Methods. Data represent means \pm SD of three independent experiments. $*$ indicates significant difference as compared to the untreated control group $(P<0.05)$. (c-d) H1650 and A549 cells were transfected with control or STAT3 overexpression plasmids for 24 h, followed by exposure of the cells to FZKA for an additional $24 \mathrm{~h}$. The protein expression levels of Bcl-2, Mcl-1, and Bax were detected by Western blot. $\beta$-Actin was used as an internal control. (e) A schematic diagram shows that FZKA induces lung cancer cell apoptosis through inactivation of STAT3, followed by reducing antiapoptotic proteins $\mathrm{Bcl}-2$ and $\mathrm{Mcl}-1$, while inducing proapoptotic protein Bax. This activates caspase-3/9 and concomitantly increases p27 expression, thereby leading to cell apoptosis. Our findings uncover an additional mechanism underlying the induction of apoptosis by FZKA and suggest that the FZKA-induced lung cancer cell apoptosis is mainly through activation of intrinsic apoptosis pathway. 
509013044060), the Chinese Medicine Science and Technology Research Project of Guangdong Provincial Hospital of Chinese Medicine (YN2016QJ03), the Guangzhou Science and Technology Plan Project (201804010149), the Guangdong Medical Science and Technology Research Foundation (A2018251), the Science and Technology Planning Project of Guangdong Province (no. 2017B030314166), and the Science and Technology Program of Guangzhou (20150429090456547).

\section{References}

[1] R. Siegel, J. Ma, Z. Zou, and A. Jemal, "Cancer statistics, 2014," CA: A Cancer Journal for Clinicians, vol. 64, no. 1, pp. 9-29, 2014.

[2] W. Chen, R. Zheng, S. Zhang et al., "Report of incidence and mortality in China cancer registries, 2009," Chinese Journal of Cancer Research, vol. 25, pp. 10-21, 2013.

[3] A. Verdecchia, S. Francisci, H. Brenner et al., "Recent cancer survival in Europe: a 2000-02 period analysis of EUROCARE-4 data," The Lancet Oncology, vol. 8, no. 9, pp. 784-796, 2007.

[4] X.-J. Zhou, M. Liu, J.-J. Yan, Y. Cao, and P. Liu, "Antidepressantlike effect of the extracted of Kai Xin San, a traditional Chinese herbal prescription, is explained by modulation of the central monoaminergic neurotransmitter system in mouse," Journal of Ethnopharmacology, vol. 139, no. 2, pp. 422-428, 2012.

[5] Y. Han, H. Wang, W. Xu et al., "Chinese herbal medicine as maintenance therapy for improving the quality of life for advanced non-small cell lung cancer patients," Complementary Therapies in Medicine, vol. 24, pp. 81-89, 2016.

[6] S. J. Shen, Y. H. Zhang, X. X. Gu, S. J. Jiang, and L. J. $\mathrm{Xu}$, "Yangfei Kongliu Formula, a compound Chinese herbal medicine, combined with cisplatin, inhibits growth of lung cancer cells through transforming growth factor-betal signaling pathway," Journal of integrative medicine, vol. 15, pp. 242-251, 2017.

[7] J. Mondal, A. Samadder, and A. R. Khuda-Bukhsh, "Psorinum $6 \times$ triggers apoptosis signals in human lung cancer cells," Journal of Integrative Medicine, vol. 14, no. 2, pp. 143-153, 2016.

[8] X.-B. Yang, W.-Y. Wu, S.-Q. Long et al., "Fuzheng Kang'ai decoction combined with gefitinib in advanced non-small cell lung cancer patients with epidermal growth factor receptor mutations: Study protocol for a randomized controlled trial," Trials, vol. 16, no. 1, article no. 146, 2015.

[9] W.-Y. Wu, X.-B. Yang, H. Deng et al., "Treatment of advanced non-small cell lung cancer with extracorporeal high frequency thermotherapy combined with Chinese medicine," Chinese Journal of Integrative Medicine, vol. 16, no. 5, pp. 406-410, 2010.

[10] X.-B. Yang, W.-Y. Wu, S.-Q. Long, H. Deng, and Z.-Q. Pan, "Effect of gefitinib plus Chinese herbal medicine (CHM) in patients with advanced non-small-cell lung cancer: a retrospective case-control study," Complementary Therapies in Medicine, vol. 22, no. 6, pp. 1010-1018, 2014.

[11] F. Zheng, J. Wu, X. Li et al., "Chinese Herbal Medicine Fuzheng Kang-Ai Decoction Inhibited Lung Cancer Cell Growth through AMPK $\alpha$-Mediated Induction and Interplay of IGFBP1 and FOXO3a," Evidence-Based Complementary and Alternative Medicine, vol. 2016, Article ID 5060757, 15 pages, 2016.

[12] L. Li, S. Wang, F. Zheng, W. Wu, and S. S. Hann, "Chinese herbal medicine Fuzheng Kang-Ai decoction sensitized the effect of gefitinib on inhibition of human lung cancer cells through inactivating PI3-K/Akt -mediated suppressing MUC1 expression," Journal of Ethnopharmacology, vol. 194, pp. 918929, 2016.

[13] D. Xiao and S. V. Singh, "Diallyl trisulfide, a constituent of processed garlic, inactivates Akt to trigger mitochondrial translocation of BAD and caspase-mediated apoptosis in human prostate cancer cells," Carcinogenesis, vol. 27, no. 3, pp. 533-540, 2006.

[14] Y. Wang, J. Yang, L. Chen et al., "Artesunate induces apoptosis through caspase-dependent and -independent mitochondrial pathways in human myelodysplastic syndrome SKM-1 cells," Chemico-Biological Interactions, vol. 219, pp. 28-36, 2014.

[15] A. Frenzel, F. Grespi, W. Chmelewskij, and A. Villunger, "Bcl2 family proteins in carcinogenesis and the treatment of cancer," Apoptosis, vol. 14, no. 4, pp. 584-596, 2009.

[16] J. D. Ly, D. R. Grubb, and A. Lawen, "The mitochondrial membrane potential $(\delta \psi \mathrm{m})$ in apoptosis; an update," Apoptosis, vol. 8, no. 2, pp. 115-128, 2003.

[17] A. G. Porter and R. U. Jänicke, "Emerging roles of caspase-3 in apoptosis," Cell Death \& Differentiation, vol. 6, no. 2, pp. 99-104, 1999.

[18] J. R. Hart, L. Liao, J. R. Yates III, and P. K. Vogt, "Essential role of stat 3 in pi3k-induced oncogenic transformation," Proceedings of the National Acadamy of Sciences of the United States of America, vol. 108, no. 32, pp. 13247-13252, 2011.

[19] W. You, Q. Tang, C. Zhang et al., "IL-26 Promotes the Proliferation and Survival of Human Gastric Cancer Cells by Regulating the Balance of STAT1 and STAT3 Activation," PLoS ONE, vol. 8, no. 5, Article ID e63588, 2013.

[20] T. G. Cotter, "Apoptosis and cancer: the genesis of a research field," Nature Reviews Cancer, vol. 9, no. 7, pp. 501-507, 2009.

[21] Y. Pan and F. X. Claret, "Targeting Jab1/CSN5 in nasopharyngeal carcinoma," Cancer Letters, vol. 326, no. 2, pp. 155-160, 2012.

[22] Y. Pan, Q. Zhang, L. Tian et al., "Jab1/CSN5 negatively regulates p27 and plays a role in the pathogenesis of nasopharyngeal carcinoma," Cancer Research, vol. 72, no. 7, pp. 1890-1900, 2012.

[23] X. Chi, J. Kale, B. Leber, and D. W. Andrews, "Regulating cell death at, on, and in membranes," Biochimica et Biophysica Acta (BBA) - Molecular Cell Research, vol. 1843, no. 9, pp. 2100-2113, 2014.

[24] S. Fulda, "Targeting apoptosis for anticancer therapy," Seminars in Cancer Biology, vol. 31, pp. 84-88, 2015.

[25] K. Cosentino and A. J. García-Sáez, "Mitochondrial alterations in apoptosis," Chemistry and Physics of Lipids, vol. 181, pp. 62-75, 2014.

[26] S. W. G. Tait and D. R. Green, "Mitochondrial regulation of cell death," Cold Spring Harbor Perspectives in Biology, vol. 5, no. 9, 2013.

[27] D. R. Green and J. C. Reed, "Mitochondria and apoptosis," Science, vol. 281, no. 5381, pp. 1309-1312, 1998.

[28] S. Ghatan, S. Larner, Y. Kinoshita et al., "p38 MAP kinase mediates Bax translocation in nitric oxide-induced apoptosis in neurons," The Journal of Cell Biology, vol. 150, no. 2, pp. 335-347, 2000.

[29] P. H. Yin, X. Liu, Y. Y. Qiu et al., "Anti-tumor activity and apoptosis-regulation mechanisms of bufalin in various cancers: new hope for cancer patients," Asian Pacific Journal of Cancer Prevention, vol. 13, no. 11, pp. 5339-5343, 2012.

[30] H. Wang, F. Lafdil, X. Kong, and B. Gao, "Signal transducer and activator of transcription 3 in liver diseases: a novel therapeutic target," International Journal of Biological Sciences, vol. 7, no. 5, pp. 536-550, 2011. 
[31] L. Tao, G. Huang, R. Wang et al., "Cancer-associated fibroblasts treated with cisplatin facilitates chemoresistance of lung adenocarcinoma through IL-11/IL-11R/STAT3 signaling pathway," Scientific Reports, vol. 6, Article ID 38408, 2016.

[32] S. I. Grivennikov and M. Karin, "Dangerous liaisons: STAT3 and NF- $\kappa$ B collaboration and crosstalk in cancer," Cytokine \& Growth Factor Reviews, vol. 21, no. 1, pp. 11-19, 2010.

[33] T. J. Shackleford and F. X. Claret, "JAB1/CSN5: A new player in cell cycle control and cancer," Cell Division, vol. 5, article no. 26, 2010.

[34] T. J. Shackleford, Q. Zhang, L. Tian et al., "Stat3 and CCAAT/ enhancer binding protein beta (C/EBP-beta) regulate Jab1/ CSN5 expression in mammary carcinoma cells," Breast Cancer Research, vol. 13, no. 3, article no. R65, 2011.

[35] C. J. Sherr and J. M. Roberts, "CDK inhibitors: positive and negative regulators of G1-phase progression," Genes \& Development, vol. 13, no. 12, pp. 1501-1512, 1999. 


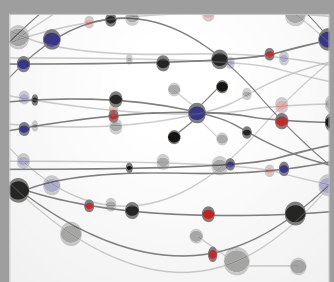

The Scientific World Journal
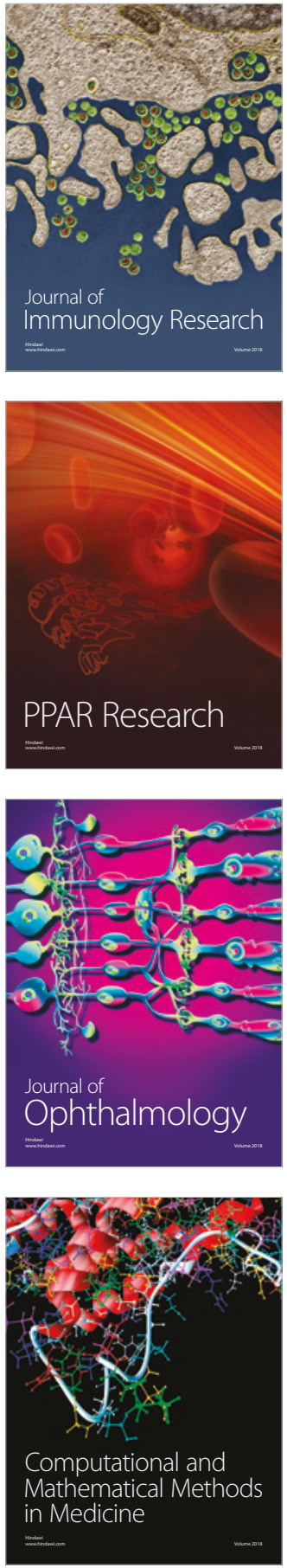

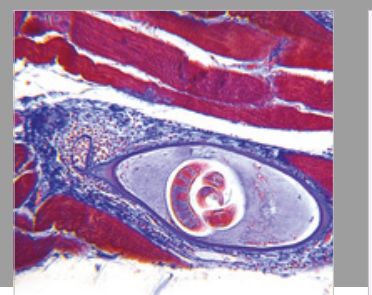

Gastroenterology Research and Practice

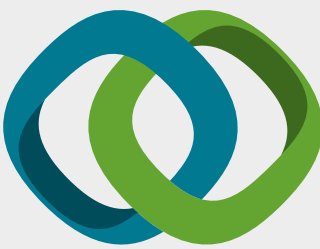

\section{Hindawi}

Submit your manuscripts at

www.hindawi.com
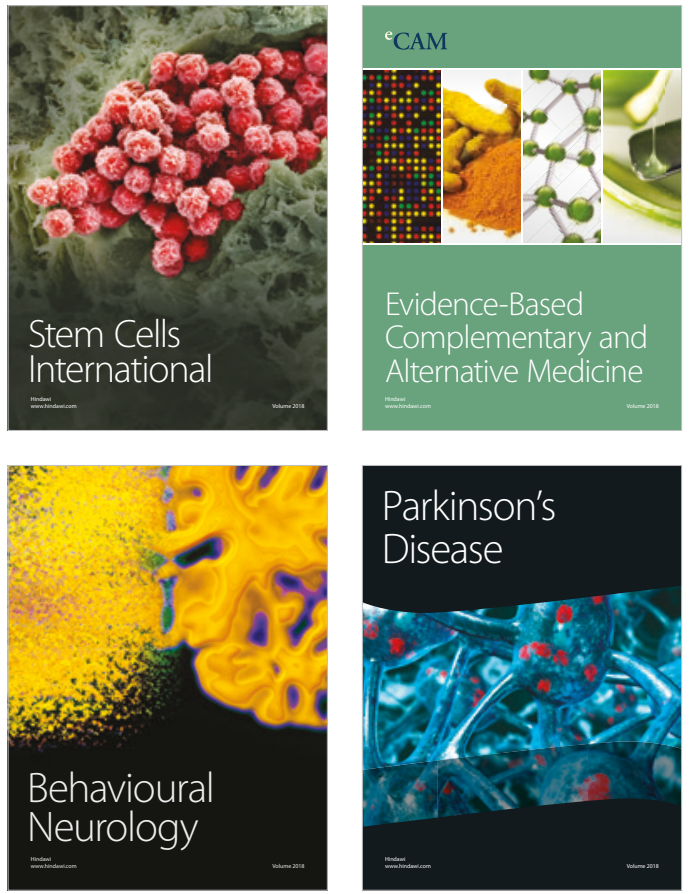

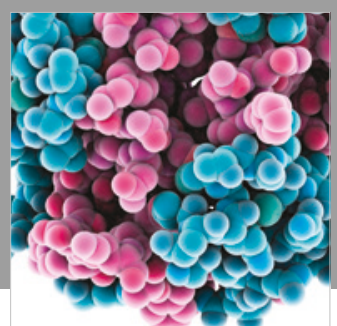

ournal of

Diabetes Research

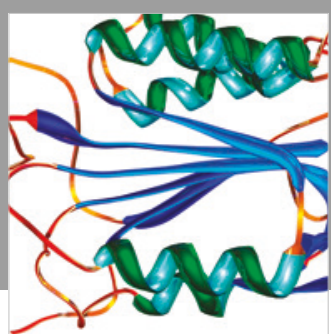

Disease Markers
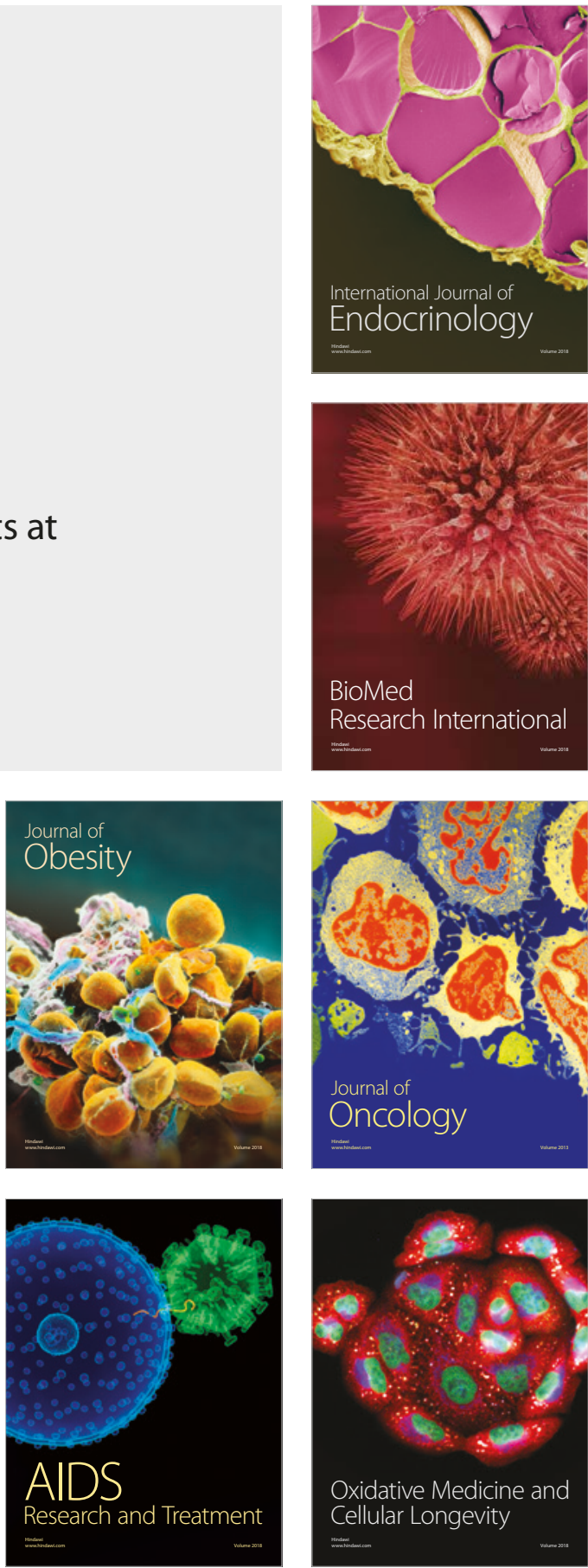